\title{
Species-specific effects of thermal stress on the expression of genetic variation across a diverse group of plant and animal taxa under experimental conditions
}

\author{
Klaus Fischer $\mathbb{D}^{1} \cdot$ Jürgen Kreyling ${ }^{2}$ Michaël Beaulieu ${ }^{1} \cdot$ Ilka Beil $^{2} \cdot$ Manuela Bog $^{2} \cdot$ Dries Bonte $^{3} \cdot$ Stefanie Holm $^{2}$. \\ Sabine Knoblauch ${ }^{2} \cdot{\text { Dustin } \mathrm{Koch}^{2} \cdot \text { Lena Muffler }^{2} \cdot \text { Pierick Mouginot }^{1} \cdot \text { Maria Paulinich }^{1} \cdot \text { J. F. Scheepens }}^{4}$. \\ Raijana Schiemann ${ }^{1} \cdot$ Jonas Schmeddes ${ }^{2} \cdot$ Martin Schnittler $^{2} \cdot$ Gabriele Uhl $^{1}$ • \\ Marieke van der Maaten-Theunissen ${ }^{2,7} \cdot$ Julia M. Weier $^{1} \cdot$ Martin Wilmking $^{2} \cdot$ Robert Weigel $^{2} \cdot$ Phillip Gienapp $^{5,6}$
}

Received: 25 March 2020 / Revised: 21 June 2020 / Accepted: 24 June 2020 / Published online: 6 July 2020

(c) The Author(s), under exclusive licence to The Genetics Society 2020

\begin{abstract}
Assessing the genetic adaptive potential of populations and species is essential for better understanding evolutionary processes. However, the expression of genetic variation may depend on environmental conditions, which may speed up or slow down evolutionary responses. Thus, the same selection pressure may lead to different responses. Against this background, we here investigate the effects of thermal stress on genetic variation, mainly under controlled laboratory conditions. We estimated additive genetic variance $\left(V_{A}\right)$, narrow-sense heritability $\left(h^{2}\right)$ and the coefficient of genetic variation $\left(C V_{A}\right)$ under both benign control and stressful thermal conditions. We included six species spanning a diverse range of plant and animal taxa, and a total of 25 morphological and life-history traits. Our results show that (1) thermal stress reduced fitness components, (2) the majority of traits showed significant genetic variation and that (3) thermal stress affected the expression of genetic variation $\left(V_{A}, h^{2}\right.$ or $\left.C V_{A}\right)$ in only one-third of the cases ( 25 of 75 analyses, mostly in one clonal species). Moreover, the effects were highly species-specific, with genetic variation increasing in 11 and decreasing in 14 cases under stress. Our results hence indicate that thermal stress does not generally affect the expression of genetic variation under laboratory conditions but, nevertheless, increases or decreases genetic variation in specific cases. Consequently, predicting the rate of genetic adaptation might not be generally complicated by environmental variation, but requires a careful case-by-case consideration.
\end{abstract}

Associate editor: Sara Knott

Supplementary information The online version of this article (https:// doi.org/10.1038/s41437-020-0338-4) contains supplementary material, which is available to authorized users.

Klaus Fischer

klausfischer@uni-koblenz.de

1 Zoological Institute and Museum, University of Greifswald, Greifswald, Germany

2 Institute of Botany and Landscape Ecology, University of Greifswald, Greifswald, Germany

3 Terrestrial Ecology Unit, Department of Biology, Ghent University, Gent, Belgium

\section{Introduction}

Humanity is currently modifying the Earth's environmental conditions at an unprecedented rate (Sala et al. 2000; Ceballos et al. 2017). Consequently, organisms are forced to respond to these vast environmental changes, by means of phenotypic plasticity, genetic in situ adaptation or by shifting their distribution range (Berg et al. 2010; Hoffmann and Sgro 2011; Lenoir and Svenning 2014). If adaptive or

4 Plant Evolutionary Ecology, Institute of Evolution and Ecology, University of Tübingen, Tübingen, Germany

5 Department of Animal Ecology, Netherlands Institute of Ecology, Wageningen, The Netherlands

6 Michael-Otto-Institut im NABU, Bergenhusen, Germany

7 Present address: Chair of Forest Growth and Woody Biomass Production, TU Dresden, Tharandt, Germany 
dispersal capacities are not sufficient, the respective species or populations will go extinct (Thomas et al. 2004; Hoffmann and Sgro 2011). In fact, many organisms seem to have been unable to keep pace with the current rate and extent of changes induced by human activities, which is resulting in a global mass extinction (Barnosky et al. 2011; Ceballos et al. 2015, 2017). Therefore, assessing the adaptive potential of extant populations and species is of crucial importance in basic as well as applied contexts.

While in the short term, phenotypic plasticity and dispersal may be appropriate responses to environmental change, genetic adaptation is likely necessary in the long term (Gienapp et al. 2008, 2014). Genetic adaptation depends on (1) the strength of selection and (2) the additive genetic variation present in the given population (Falconer and Mackay 1996). However, there is evidence that not only the strength of selection, but also the expression of genetic variation depends on environmental conditions (Hoffmann and Parsons 1991; Falconer and Mackay 1996; Hoffmann and Merila 1999; Charmantier and Garant 2005; Ghalambor et al. 2007). Mechanisms underlying environmental impacts on the expression of genetic variation may involve (1) reduced expression of additive genetic variance, (2) higher environmental variance, (3) low crossenvironment genetic correlations/conditionally expressed genetic variation or (4) the release of cryptic genetic variation (Hoffmann \& Parsons 1991; Hoffmann and Merila 1999; Charmantier and Garant 2005; Ghalambor et al. 2007). Note that (4) does not allow for any predictions concerning the direction of change in genetic variation (Charmantier and Garant 2005). It has also been suggested that drastic environmental changes may result in altered genetic variation triggered by the expression of new sets of genes (Hoffmann and Parsons 1991; Charmantier and Garant 2005).

Provided there is a close relationship between the expression of genetic variation and evolutionary change, covariance between environmental condition and the expression of genetic variation may speed up (in case it is positive) or slow down (if negative) evolutionary responses (Wood and Brodie 2016; Ramakers et al. 2018). This may have important implications, as the same selection pressure may lead to different responses, depending on environmental conditions (Hoffmann and Merila 1999; Rowinski and Rogell 2017). For instance, evolutionary adaptation may be constrained due to a lack of additive genetic variation in specific environments (Hoffmann and Merila 1999; Kellermann et al. 2009). In any case, the environmental dependence of the expression of genetic variation complicates predictions on the rate of genetic adaptation. This may at least partly explain why reliably forecasting the fate of species and populations under rapidly changing environmental conditions has remained largely elusive (Chevin et al. 2010; Gienapp et al. 2013; Moritz and Agudo 2013; Boyd et al. 2018). Thus, understanding the interactions between environment and the expression of quantitative genetic variation is important for predicting the rate of genetic adaptation (Rowinski and Rogell 2017). Note though that the wide-held notion of a close relationship between genetic variation and evolutionary response has been tested surprisingly rarely, and associations may be weaker than expected (Wood et al. 2016; Hoffmann et al. 2017; Ørsted et al. 2019).

The question of whether the expression of genetic variation differs consistently between stressful and benign conditions has attracted considerable attention (Hoffmann and Merila 1999; Rowinski and Rogell 2017). Several hypotheses have been proposed, ranging from expectations of lower, higher and ambiguous changes in genetic variation under stress (summarized in Rowinski and Rogell 2017). A general pattern though remains elusive (Hoffmann and Parsons 1991; Hoffmann and Merila 1999; Merilä et al. 2001; Charmantier and Garant 2005; Rowinski and Rogell 2017). One reason for the limited support for a general impact of stressful conditions on the expression of genetic variation may be a focus on trait heritability in previous studies (Falconer and Mackay 1996). However, heritability depends on the total phenotypic variation, and residual variation may also be sensitive to environmental conditions (Houle 1992; Hoffmann and Merila 1999; Rowinski and Rogell 2017). Interestingly, a recent meta-analysis in animals did not reveal a clear pattern in heritability between stressful and benign conditions, while the coefficient of genetic variation was higher under stressful than under benign conditions, though only in life history but not in morphological traits (Rowinski and Rogell 2017).

In summary, while it is clear that environmental conditions may affect the expression of genetic variation, it is still not resolved whether stressful conditions generally increase or decrease genetic variation, calling for more empirical data. We here provide such data by investigating six species spanning a diverse range of taxa, including three plant and three arthropod species. A strength of our approach is that we mainly present data obtained from controlled experiments, thus reducing environmental variation. As a drawback, laboratory conditions are evidently far away from natural ones, such that any extrapolations to the field are difficult.

Per species, we measured several traits, including at least one morphological and one 'life-history' trait, with heritability being typically lower in the latter (Roff 2002). For each species, we estimated additive genetic variance $\left(V_{A}\right)$, narrow-sense heritability $\left(h^{2}\right)$ and the coefficient of genetic variation $\left(C V_{A}\right)$ under both benign control and stressful thermal conditions. $C V_{A}$ was included as it provides a measure of evolutionary potential relative to the trait mean, 
whilst $V_{A}$ scales with trait means, and $h^{2}$ is additionally affected by non-genetic variance components (Houle 1992; Rowinski and Rogell 2017). Thus, $C V_{A}$ may allow leastbiased comparisons of evolutionary potential. Nevertheless, quantitative assessments of how $C V_{A}$ changes across stressful and benign conditions are largely lacking (but see Rowinski and Rogell 2017). We also investigate the effects of thermal stress on life-history traits (measured as indicators of fitness components) to demonstrate that stress was imposed. We hypothesise that (1) stress treatments will negatively affect fitness components, (2) 'standardised' genetic variation $\left(h^{2}, C V_{A}\right)$ is on average higher in morphological than in life-history traits (Roff 2002) and that (3) stress will affect the expression of genetic variation $\left(V_{A}, h^{2}\right.$, $C V_{A}$ ). Testing these hypotheses is of broad significance to contemporary eco-evolutionary research, as evolutionary potential may increase in populations exposed to stressful conditions, which may in turn mitigate detrimental effects of human-induced global change (Hoffmann and Merila 1999; Gienapp et al. 2008, 2014; Wood and Brodie 2016; Rowinski and Rogell 2017).

\section{Materials and methods}

\section{Study organisms}

For this study, we investigated six species from various taxonomic groups, including three plant and three animal (arthropod) species. We used these six species to cover a broad taxonomic range and different life styles. Each species should be regarded as a biological replicate to test the hypotheses outlined above.

\section{Plant species studied}

The three plants species studied were Arabidopsis thaliana (L.) Heynh., Spirodela polyrhiza (L.) Schleid. and Fagus sylvatica $\mathrm{L}$. A. thaliana is a small, annual plant with a short life cycle, and is native to Eurasia and Africa, where it is mainly found at roadsides and other ruderal habitats. It is a popular model organism in plant biology and genetics (Ågren and Schemske 2012). The seeds for the parental generation used here originated from botanical gardens in Nantes, France and Bremen, Germany, and were pooled for experiments in order to ensure high genetic variation that may be reduced within individual source population in an almost exclusively selfing species (Mitchell-Olds and Schmitt 2006). S. polyrhiza is a small, free-floating, mainly vegetatively reproducing freshwater plant with a cosmopolitan distribution (Landolt 1986). It is highly reduced in morphology with a leaf-like plant body, henceforth referred to as 'frond' (Landolt 1986). For investigation, 28 clones with different worldwide origins from the duckweed stock collection of the University of Jena, Germany, were used. $F$. sylvatica is the dominant native forest tree species of Central Europe and thrives under a wide range of climatic and environmental conditions (Leuschner et al. 2006). Yet, $F$. sylvatica is expected to suffer from climate change due to low seed-dispersal capacity and high drought sensitivity (Jump et al. 2006; Hacket-Pain et al. 2016). We used trees from eight sites across the natural range of the species (see further below).

\section{Animal species studied}

The three arthropods were the butterfly Bicyclus anynana (Butler, 1879), the beetle Tribolium castaneum (Herbst, 1797) and the spider mite Tetranychus urticae (Koch 1836). $B$. anynana is a tropical, fruit-feeding butterfly, ranging from southern Africa to Ethiopia (Larsen 1991). These animals used here originated from a well-established laboratory stock population that had been found at Greifswald University, Germany, in 2008 (Klockmann et al. 2016). T. castaneum, the red flour beetle, is a common pest of stored food products. It originates from the IndoAustralian region, but now has a worldwide distribution (Mahroof et al. 2003). Two populations, namely the San Bernardino and the Georgia-2 strain, both provided by the University of Gießen, Germany, were used. T. urticae is a globally distributed haplodiploid herbivorous mite. Fertilised females can produce fertilised and unfertilised eggs, which develop into females and males, respectively (Helle 1967). All individuals used here originated from the stock population of Ghent University, Belgium, originally collected from roses more than 10 years ago (Van Leeuwen et al. 2008). Stocks are kept and maintained on potted bean plants, Phaseolus vulgaris, at room temperature.

\section{Experimental design}

All species used, except Fagus (see below), were initially reared under common environmental conditions. The parental $(\mathrm{P})$ generation was then divided among two temperature groups, a thermal control and a thermal stress treatment with increased temperature. The temperatures chosen were based on prior experience with the study organisms, including pretrials and previously reported results (see further below). We tested whether stress treatments were actually stressful in all cases (see 'Results'). To control for environmental and parental effects, all individuals and their offspring (F1 and F2 generations) were afterwards kept exclusively at the conditions they were originally assigned to. Thus, the offspring of each group was raised for two generations (F1 and F2) at the respective temperatures. The F1-generation individuals 
Table 1 Effects of thermal stress on various traits in six plant and animal species (F1 generation).

\begin{tabular}{|c|c|c|c|c|c|c|c|c|}
\hline Species & Trait & Type & Control & Stress & $n_{c}$ & $n_{s}$ & Stress effect & Significance \\
\hline \multirow[t]{4}{*}{ Arabidopsis thaliana } & Leaf length $[\mathrm{mm}]$ & M & $29.13 \pm 0.49$ & $36.81 \pm 0.98$ & 77 & 76 & + & $* * *$ \\
\hline & Specific leaf area $\left[\mathrm{mm}^{2} / \mathrm{mg}\right]$ & M & $66.87 \pm 1.08$ & $61.91 \pm 1.57$ & 77 & 75 & - & $* * *$ \\
\hline & Shoot length [mm] & M & $32.51 \pm 0.52$ & $35.06 \pm 1.07$ & 68 & 76 & + & $* * *$ \\
\hline & Germination rate $[\%]$ & $\mathrm{L}$ & $0.93 \pm 0.02$ & $0.84 \pm 0.02$ & 67 & 66 & - & $*$ \\
\hline \multirow[t]{5}{*}{ Spirodela polyrhiza } & Relative growth rate $\left[\right.$ day $\left.^{-1}\right]$ & $\mathrm{L}$ & $0.409 \pm 0.006$ & $0.400 \pm 0.007$ & 28 & 28 & - & $*$ \\
\hline & Fronds/colony $[n]$ & M & $8.6 \pm 0.3$ & $7.7 \pm 0.2$ & 28 & 28 & - & $* * *$ \\
\hline & Area:weight ratio $\left[\mathrm{cm}^{2} / \mathrm{g} \mathrm{dw}\right]$ & M & $662.2 \pm 17.8$ & $721.7 \pm 22.2$ & 28 & 28 & + & $* * *$ \\
\hline & TBARS $[\mu \mathrm{mol} / \mathrm{g} \mathrm{fw}]$ & $\mathrm{L}$ & $0.046 \pm 0.004$ & $0.033 \pm 0.002$ & 27 & 27 & - & $* * *$ \\
\hline & ANT $[\mu \mathrm{mol} / \mathrm{g} \mathrm{fw}]$ & $\mathrm{L}$ & $0.142 \pm 0.010$ & $0.084 \pm 0.003$ & 24 & 24 & - & $* * *$ \\
\hline \multirow[t]{3}{*}{ Fagus sylvatica } & Leaf area $\left[\mathrm{cm}^{2}\right]$ & M & $11.99 \pm 1.43$ & $10.54 \pm 0.79$ & 15 & 15 & - & $* * *$ \\
\hline & Specific leaf area $\left[\mathrm{mm}^{2} / \mathrm{mg}\right]$ & M & $18.33 \pm 1.78$ & $17.93 \pm 1.22$ & 15 & 15 & - & $* * *$ \\
\hline & Growth (z-transformed) & $\mathrm{L}$ & $0.84 \pm 0.16$ & $-0.79 \pm 0.14$ & 15 & 15 & - & $*$ \\
\hline \multirow[t]{5}{*}{ Bicyclus anynana } & Wing length $[\mathrm{mm}]$ & M & $19.8 \pm 0.1$ & $18.2 \pm 0.1$ & 101 & 103 & - & $* * *$ \\
\hline & Thorax mass [mg] & M & $17.7 \pm 0.3$ & $12.8 \pm 0.3$ & 101 & 103 & - & $* * *$ \\
\hline & Fat content $[\%]$ & $\mathrm{L}$ & $23.5 \pm 1.0$ & $29.9 \pm 1.1$ & 101 & 102 & + & $*$ \\
\hline & Fecundity $[n]$ & $\mathrm{L}$ & $99.2 \pm 5.2$ & $69.8 \pm 3.8$ & 49 & 51 & - & $* * *$ \\
\hline & Heat tolerance $[s]$ & $\mathrm{L}$ & $1819.1 \pm 73.2$ & $2344.6 \pm 83.4$ & 90 & 76 & + & $* *$ \\
\hline \multirow[t]{5}{*}{ Tribolium castaneum } & Body length [mm] & M & $3.73 \pm 0.01$ & $3.56 \pm 0.02$ & 118 & 73 & - & $* * *$ \\
\hline & Body mass [mg] & M & $2.35 \pm 0.02$ & $2.15 \pm 0.03$ & 119 & 73 & - & $* *$ \\
\hline & Cold tolerance $[s]$ & $\mathrm{L}$ & $615.5 \pm 19.4$ & $1117.1 \pm 49.6$ & 176 & 148 & - & $* * *$ \\
\hline & Heat tolerance $[s]$ & $\mathrm{L}$ & $689.2 \pm 22.9$ & $827.4 \pm 44.6$ & 151 & 134 & + & $*$ \\
\hline & Fecundity $[n]$ & $\mathrm{L}$ & $76.1 \pm 4.0$ & $59.5 \pm 5.4$ & 57 & 32 & - & $*$ \\
\hline \multirow[t]{3}{*}{ Tetranychus urticae } & Body size $[\mathrm{mm}]$ & M & $0.33 \pm 0.003$ & $0.32 \pm 0.003$ & 489 & 495 & & n.s. \\
\hline & Fecundity $[n]$ & $\mathrm{L}$ & $41.7 \pm 1.1$ & $28.9 \pm 1.2$ & 223 & 226 & - & $* * *$ \\
\hline & Heat survival $[0 / 1]$ & $\mathrm{L}$ & $0.697 \pm 0.024$ & $0.698 \pm 0.022$ & 445 & 431 & & n.s. \\
\hline
\end{tabular}

The plants Arabidopsis thaliana, Spirodela polyrhiza and Fagus sylvatica, the butterfly Bicyclus anynana, the beetle Tribolium castaneum and the spider mite Tetranychus urticae were included in our analyses. Given are type of trait (M: morphological trait, L: life-history trait), means \pm SE, sample sizes for control $\left(n_{c}\right)$ and stress treatment $\left(n_{s}\right)$, stress effect $(+$ : stress beneficial; - : stress detrimental) and level of significance $(* * * p<$ $0.0001, * * p<0.001, * p<0.05)$.

TBARS thiobarbituric acid-reactive substances, $A N T$ anthocyanin content.

were used for measuring trait values and to set up full-sib families. Per species, 3-5 traits were measured, always including at least one morphological (i.e., size-related) and one life-history trait (including survival rate, fecundity, stress tolerance, growth rate and physiological traits, Table 1). Differences in the number and nature of the traits measured result from variation in the respective species' biology. Morphological traits frequently have higher heritabilities than life-history traits, with the latter often being more closely related to fitness. This difference may result from a higher residual variation in life-history traits (Houle 1992; Roff 2002). The F2 generation was raised in full-sib family groups, and the same traits were assessed as in the F1 generation. All traits and measures of genetic variation were thus assessed under both control and stress conditions. The number of full-sib families ranged between 15 and 75 , depending on species, treatment and trait. For details see Supplementary Table 1.

\section{Experiments with Arabidopsis thaliana}

In A. thaliana, the two treatments involved constant temperatures of $22^{\circ} \mathrm{C}$ (control) or $28^{\circ} \mathrm{C}$ (stress, based on pretrials quantifying growth and fecundity at different temperature extremes), using a photoperiod of L16:D8 at $300 \mu \mathrm{mol} \mathrm{m}^{-2} \mathrm{~s}^{-1}$ photosynthetically active radiation (PAR) throughout. Plants were grown in climate chambers (LT-36 VL, Percival Scientific) in individual pots containing standard potting soil after stratification $\left(1\right.$ week at $\left.4{ }^{\circ} \mathrm{C}\right)$. Pots were watered and rearranged daily to avoid position effects. Arabidopsis thaliana is almost exclusively selfing (Mitchell-Olds and Schmitt 2006), and thus seeds for the subsequent generations were sampled directly from the parental plant. Note that selfing in flowering plants (with unisexual gametophytes) is expected to maintain a considerable genetic variance, as the full reproductive cycle with independent recombination events is kept. Leaf length and 
specific leaf area (SLA, i.e., leaf area per dry weight (dw)) were measured at day 25 for the three largest leaves per plant. Shoot length was measured at seed ripening (day 62 for $28{ }^{\circ} \mathrm{C}$ and day 69 for $22^{\circ} \mathrm{C}$ ). In addition to these morphological traits, germination rate of about 40 seeds per plant (12 days at $22^{\circ} \mathrm{C}$ and 24 -h light, after stratification) was determined as fitness component.

\section{Experiments with Spirodela polyrhiza}

Spirodela polyrhiza clones $(n=28)$ were taken from the stock collection and pre-cultivated under axenic conditions at $26{ }^{\circ} \mathrm{C}$ for a minimum of 3 weeks in $170 \mathrm{~mL}$ of sterile medium $\left(8 \mathrm{mM} \mathrm{KNO}_{3}, 150 \mu \mathrm{M} \mathrm{K \textrm {KH } _ { 2 } \mathrm { PO } _ { 4 } , 1 \mathrm { mM } \mathrm { MgSO }} 4\right.$, $1 \mathrm{mM} \mathrm{Ca}\left(\mathrm{NO}_{3}\right)_{2}, 5 \mu \mathrm{M} \mathrm{H}_{3} \mathrm{BO}_{3}, 0.4 \mu \mathrm{M} \mathrm{Na} \mathrm{MoO}_{4}, 13 \mu \mathrm{M}$ $\mathrm{MnCl}_{2}$ and $25 \mu \mathrm{M}$ FeNaEDTA; Appenroth et al. 1996), which was replaced every week to prevent nutrient limitation. Plants were kept under continuous light at $100 \mu \mathrm{mol} \mathrm{m}$ ${ }^{-2} \mathrm{~s}^{-1}$ PAR throughout (Naumann et al. 2007). For testing, up to 12 fronds per clone were transferred to $400-\mathrm{mL}$ glass beakers (covered by glass plates) with $300 \mathrm{~mL}$ of autoclaved medium each, and exposed to either $26^{\circ} \mathrm{C}$ (control) or $32^{\circ} \mathrm{C}$. A minimum of five replicate beakers was used per temperature and clone. After 2 days of acclimation, the number of fronds per beaker was scored and, if necessary, reduced to a maximum number of 20 fronds to prevent crowding. After another 7 days, the number of fronds was counted, and the number of fronds connected by stolons (=fronds/colony, $F / C$ ) was determined. Eight to ten colonies per replicate were taken for area measurements using a commercial scanner and the software ImageJ (v1.51j8). After $24 \mathrm{~h}$ at $80^{\circ} \mathrm{C}, \mathrm{dw}$, including roots of the scanned material, was determined to calculate an area:weight ratio (AWR, $\mathrm{cm}^{2} / \mathrm{g} \mathrm{dw}$ ). About $50 \mathrm{mg}$ of the remaining fresh plant material was stored at $4{ }^{\circ} \mathrm{C}$, and a second portion of $50 \mathrm{mg}$ was kept at $-18{ }^{\circ} \mathrm{C}$ for further analyses, respectively. The relative growth rate $\left(\mathrm{day}^{-1}\right)$ was calculated from the number of fronds according to Ziegler et al. (2015). The frozen plant material was used for photometrical determination of the anthocyanin content (ANT, $\mu \mathrm{mol} / \mathrm{g}$ fresh weight (fw); Sims and Gamon 2002). Thiobarbituric acidreactive substances (TBARS, $\mu \mathrm{mol} / \mathrm{g} \mathrm{fw}$ ), measured as malondialdehyde equivalents, were determined photometrically from the $4{ }^{\circ} \mathrm{C}$-stored plant material following Cvjetko et al. (2010). TBARS, as a measure of lipid peroxidation caused by free radicals (Janero 1990), as well as ANT, being related to antioxidative abilities (Tsuda et al. 1996), are considered fitness proxies in plants.

\section{Experiments with Fagus sylvatica}

Fagus sylvatica was not assessed by laboratory trials due to its long lifespan. However, our goal was to include a broad variety of taxa, and long-lived tree species are clearly relevant though not amenable to controlled lab experiments. Instead, we sampled open-pollinated seeds (representing half-sibs) of 30 mature parental trees at eight sites across the natural range of the species in Sweden (SE, 2 parent trees only), Germany (DE, three sites), Poland (PL), Switzerland $(\mathrm{CH})$, France (FR) and Spain (ES). Genetic diversity of $F$. sylvatica is known to be very high within stands throughout the species' distribution range as compared with among-stand variation (Magri et al. 2006). We consequently assumed comparable genetic variation by sampling random mother trees, all located within large and monodominant forest stands. In addition to seeds, at least two shade leaves and two wood core samples were taken per tree. From the cores, basal area increment (BAI) was calculated for the last 20 years as the difference between consecutive cross-sectional basal areas, and standardised for a tree of $30-\mathrm{cm}$ diameter at breast height. Seeds of each parental tree were divided among 12 sites (the same eight sites as above plus one site without seeds in SE and three sites outside the current range of the species in SE, PL and ES, altogether 12.840 seeds). After one full growing season, the growth of 474 randomly selected and established seedlings was measured, and 2 leaves sampled per plant (1 leaf if the plant had only 1 leaf; on average, plants had 2.2 leaves). Leaf area and SLA as morphological traits were determined for all individuals. Growth, as a relevant lifehistory trait, was based on BAI and height growth, respectively. The mother trees were separated into a stress and a control group based on the standardised BAI (high growth rates representing benign 'control' growing conditions with $6221 \pm 335 \mathrm{~mm}^{2}$ vs. $3026 \pm 173 \mathrm{~mm}^{2}$ for stressful conditions; $t$-test $p<0.001)$. The offspring was separated into stress and control environments by transplantation sites, using a distinct split in the distribution of seedling establishment success (control: $26.1 \pm 5.3 \%$, stress $8.1 \pm$ $2.0 \%$; $t$-test $p=0.003$ ). The parent trees were used as F1 generation and their offspring as F2 for comparison with the other experiments. While the level of stress per site was quantified by evaluating all seedlings, the following analyses are based only on seeds of stressed parents transplanted to stressful sites, and on seeds of the less-stressed parents transplanted to less stressful sites, respectively.

\section{Experiments with Bicyclus anynana}

In $B$. anynana, the two treatments comprised constant temperatures of $25^{\circ} \mathrm{C}$ (control) or $29^{\circ} \mathrm{C}$ (stress; Fischer et al. 2010; Beaulieu et al. 2015), using a photoperiod of L12:D12 and a relative humidity of $70 \%$ throughout. Larvae were fed on potted, greenhouse-reared maize plants, adults on moist banana. F1-generation butterflies were set up for mating on day 2 of adult life. To ensure single 
matings, mating couples were isolated while still mating. After mating, heat-knockdown time (time until physical knockdown at a constant temperature of $43{ }^{\circ} \mathrm{C}$; Fischer et al. 2010) was measured in males, after which they were frozen at $-80{ }^{\circ} \mathrm{C}$ for later analyses. Females, in contrast, were individually set up for egg-laying after mating for 4 consecutive days to found full-sib families. On day 6 of adult life, females were also subjected to the above heatknockdown assay, after which they were frozen for later analyses. All eggs produced were counted (=fecundity) and subsequently raised as full-sib families at their respective temperature. The resulting F2 adults were subjected to the same procedure outlined above to score offspring traits. In addition to fecundity and heat tolerance, we scored wing length, thorax mass (to the nearest $0.01 \mathrm{mg}$, Sartorius LE225D, Goettingen, Germany) and relative abdomen fat content (\%) in both sexes. To measure fat content, abdomens were dried for $48 \mathrm{~h}$ at $60^{\circ} \mathrm{C}$ and weighed. Then, fat was extracted twice for $48 \mathrm{~h}$ using $1 \mathrm{~mL}$ of acetone each time. Afterwards, the abdomen was again dried for $48 \mathrm{~h}$ at $60{ }^{\circ} \mathrm{C}$ and weighed. Fat content was calculated as the mass difference between the first and the second dry mass, and is expressed as the percentage of abdomen dry mass (Fischer et al. 2003).

\section{Experiments with Tribolium castaneum}

For T. castaneum, $30{ }^{\circ} \mathrm{C}$ (control) and $35{ }^{\circ} \mathrm{C}$ (stress; Mahroof et al. 2003) were used along with a photoperiod of L12: D12 and a relative humidity of $70 \%$ throughout. Larvae and adults were fed with organic flour, to which 5\% baker's yeast was added. All resulting F1 pupae were sexed and afterwards kept separated by gender. After adult eclosion, a single male and a single female were kept together for 14 days to allow for mating and egg-laying. Afterwards, parents were removed and first subjected to a cold-tolerance assay (chill-coma recovery time, i.e., the time until legs moved again after a 2 -h exposure to $0{ }^{\circ} \mathrm{C}$ ), and 1 day later to a heat-knockdown assay $\left(\right.$ at $\left.50^{\circ} \mathrm{C}\right)$, before being frozen and stored at $-80^{\circ} \mathrm{C}$. The offspring produced was counted and used to raise full-sib families (F2). The resulting pupae and adults were treated as described above. In addition to fecundity, cold and heat tolerance, we scored body mass and length.

\section{Experiments with Tetranychus urticae}

In T. urticae, the two treatments comprised constant temperatures of $25^{\circ} \mathrm{C}$ (control) or $33^{\circ} \mathrm{C}$ (stress), using a photoperiod of L16:D8 throughout. Individuals were housed and fed on $2 \times 3.5-\mathrm{cm}^{2}$ bean leaf cuttings (Phaseolus vulgaris), placed on top of a moist cotton pad, in Petri dishes. F1-generation females were individually set up for mating on a leaf cutting with an adult male from a different family. To ensure mating with virgin females, we used females in their last quiescent stage. Couples were checked daily and considered mated when females had emerged. After mating, male body size was measured and heat survival assessed (i.e., survival after exposure to $50^{\circ} \mathrm{C}$ for $10 \mathrm{~min}$, Eppendorf thermomixer). Females were individually set up for egglaying on new leaf cuttings for 5 days to found full-sib families. On day 6 of adult life, female body size was measured, and females were subjected to the above heatsurvival assay. All eggs produced were counted (=fecundity) and subsequently raised as full-sib families at their respective temperature. The resulting F2 adults were subjected to the same procedure outlined above to score offspring traits. For body-size measurements, individuals were photographed under a stereomicroscope (Leica M80 with MC190 HD Camera) and measured using the software LAS v4.9 (Leica application suite). For egg counting, each female's leaf was photographed (Nikon D5300), and the photographs were analysed using IMAGEJ image processing and analysis software (v. 1.49).

\section{Methods for quantitative genetic analyses}

To estimate additive genetic variation $\left(V_{A}, h^{2}\right.$ and $\left.C V_{A}\right)$, 'animal models' were used (Kruuk 2004; Wilson et al. 2010). The 'animal model' is a special form of a mixed model that includes the additive genetic relatedness matrix to account for the fact that individuals in the data set are related. The additive genetic relatedness matrix is constructed from a pedigree. Here, our models included only the additive genetic effect as a random effect and various fixed factors. These (univariate) models hence took the following form:

$y_{i}=\mu+$ treat $_{i}+\operatorname{sex}_{i}+\operatorname{pop}_{i}+\operatorname{gen}_{i}+a_{i}+\varepsilon_{i}$,

where $y_{i}$ is the phenotype of individual $i$, treat ${ }_{i}$ the treatment group to which individual $i$ was assigned, $\operatorname{sex}_{i}$ the sex of individual $i$ (if applicable), $\operatorname{pop}_{i}$ the population to which individual $i$ belonged (for $T$. castaneum only), $\operatorname{gen}_{i}$ the generation to which individual $i$ belonged, $a_{i}$ the additive genetic effect of individual $i$ and $\varepsilon$ the error term. Note that not all fixed effects were fitted in each model. We did not fit a brood and a maternal effect because both generations analysed were reared under identical laboratory conditions (within each treatment).

For each trait within each species, three different models were run. In the first model, all records were analysed jointly, and treatment (plus other fixed factors if applicable) was fitted as fixed effect. This model estimated the additive genetic variance $\left(V_{A}\right)$, narrow-sense heritability $\left(h^{2}\right)$ and the coefficient of genetic variation $\left(C V_{A}\right)$ of the respective trait, accounting for the fitted fixed effects. In the second and 
third models, $V_{A}, h^{2}$ and $C V_{A}$ were estimated separately for each treatment (while retaining other fixed effects if applicable). Genetic variation $\left(V_{A}, h^{2}\right.$ and $\left.C V_{A}\right)$ significantly larger than zero was tested by comparing a model with the additive genetic component with a model without the additive genetic component with a likelihood-ratio test (LRT) with $1 \mathrm{df}$. Finally, it was tested whether $V_{A}, h^{2}$ and $C V_{A}$ differed between treatments. Towards this end, a bivariate model with the trait values of the control treatment as one phenotype and those of the stress treatment as the other phenotype was fitted. This model hence fits the following covariance matrix for the additive genetic effect:

$\boldsymbol{G}=\left[\begin{array}{cc}\operatorname{var}(z . c) & 0 \\ 0 & \operatorname{var}(z . s)\end{array}\right]$,

with $\operatorname{var}(z . c)$ being the additive genetic variance of the trait in the control environment and $\operatorname{var}(z . s)$ the additive genetic variance of the trait in the stressful environment. The genetic covariance could not be estimated because individuals in the control environment had no relatives in the stressful environment and vice versa. The results were compared with a bivariate model where the variances of the two (scaled) traits were constrained to be equal, i.e., $\operatorname{var}(z$. $c)=\operatorname{var}(z . s)$, with a LRT with $1 \mathrm{df}$. To test whether $h^{2}$ and $C V_{A}$ differed from zero and between environments, trait values were standardised (by subtracting the mean and dividing by the standard deviation) or divided by the trait mean, respectively, and the same models compared with a LRT as for $V_{A}$. In $F$. sylvatica, $C V_{A}$ of growth was calculated based on the F1-generation half-siblings only due to differences in the measurements between F1 and F2. All analyses were performed with ASReml-R, except for Spirodela. Here, 'clonal repeatability' instead of the additive genetic variation was calculated, assuming that all variation among individuals is due to additive genetic effects. Since no pedigree was available, a mixed model with individual identity as random effect was fitted with the lme4 package in R 3.3.2 (Bates and Sarkar 2007).

Because of the limited number of species studied and some differences in experimental design, we tested for the effects of treatment (stress vs. control) and trait type (morphological vs. life history) across all species and traits by meta-analyses (Borenstein et al. 2009). For each estimate of genetic variance $\left(V_{A}, h^{2}, C V_{A}\right)$, a single metaanalysis was run. In the meta-analyses, the Hedges $g$ measure of effect size was calculated as the difference between the means of the treatments or trait types, divided by the pooled respective standard deviation, and weighted by the number of traits per organism and trait class. The treatment was considered to have a statistically significant positive effect if the $95 \%$ confidence interval of the mean effect size did not include values below zero, and a statistically significant negative effect when it did not include values above zero (Gurevitch and Hedges 2001). The meta-analyses were run through the R package effsize 0.7.1 (Torchiano 2017). In addition, we used general linear mixed models (GLMMs) with treatment, trait type and their interaction as fixed effects and species as random effect. Dependent factors were the absolute values of $V_{A}$, $h^{2}$ and $C V_{A}$.

\section{Results}

\section{Effects of treatments on morphological and life- history traits}

The stress treatment significantly affected all traits measured, except body size and heat tolerance in T. urticae (Table 1 and Supplementary Table 2). Regarding morphological traits, stress conditions increased leaf and shoot length in A. thaliana and AWR in S. polyrhiza, and decreased (specific) leaf area in A. thaliana and F. sylvatica, the number of fronds per colony in $S$. polyrhiza and mass and size traits in B. anynana and $T$. castaneum. Regarding life-history traits, stress increased heat tolerance in $B$. anynana and T. castaneum, and relative fat content in B. anynana, but reduced germination rate in A. thaliana, growth rate in $S$. polyrhiza and $F$. sylvatica, TBARS, ANT in $S$. polyrhiza, cold tolerance in $T$. castaneum and fecundity in all arthropod species.

\section{Genetic variation: results of animal models}

Only in 6 out of 25 cases, no significant genetic variation was found, namely in fecundity in T. castaneum, in specific leaf area in A. thaliana and $F$. sylvatica and in heat tolerance in all three arthropod species (Table 2). Thus, significant genetic variation was found in both morphological (including leaf length, shoot length, fronds per colony, AWR, body size and mass) and life-history traits (germination and growth rate, TBARS, ANT, fat content, fecundity and cold tolerance). In five of the 19 cases in which significant genetic variation was found, though, it was not significant under either control $(1 \times)$ or stress $(4 \times)$ conditions only. Significant differences in genetic variation among treatments were found in only $10\left(V_{A}\right), 7\left(h^{2}\right)$ and 8 $\left(C V_{A}\right)$ out of the 19 traits, each showing significant genetic variation (Table 2 and Fig. 1). A notable exception is S. polyrhiza, in which all treatments differed significantly in estimates of genetic variation (thus comprising 15 out of the above 25 significant cases in which genetic variation differed among treatments). In A. thaliana, 7 out of 9 , in $F$. sylvatica 1 out of 6 , in B. anynana 2 out of 12 , in $T$. castaneum 0 out of 9 and in T. urticae 0 out of 6 cases with 
Table 2 Results of animal models estimating additive genetic variation per trait in six species.

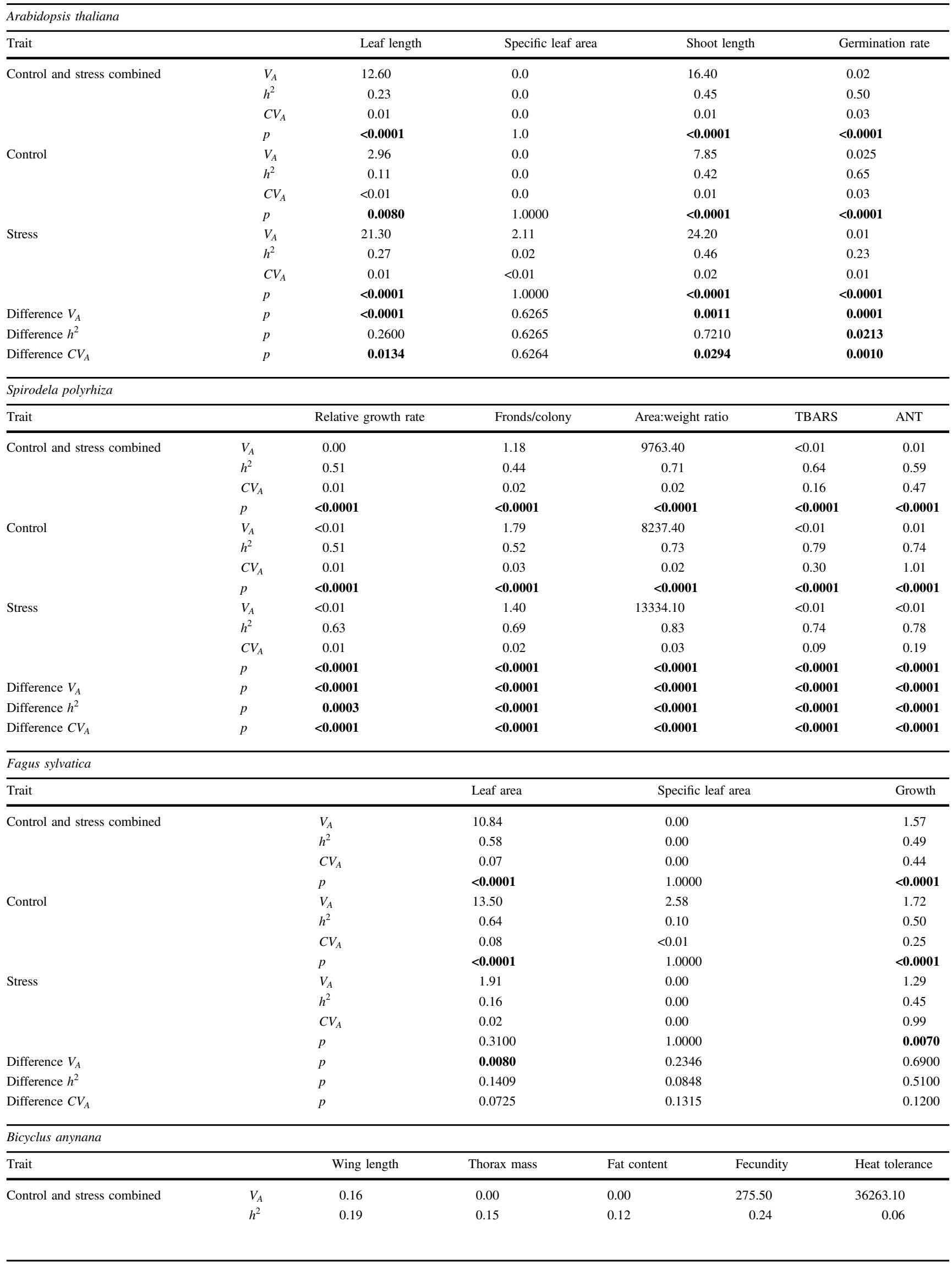


Table 2 (continued)

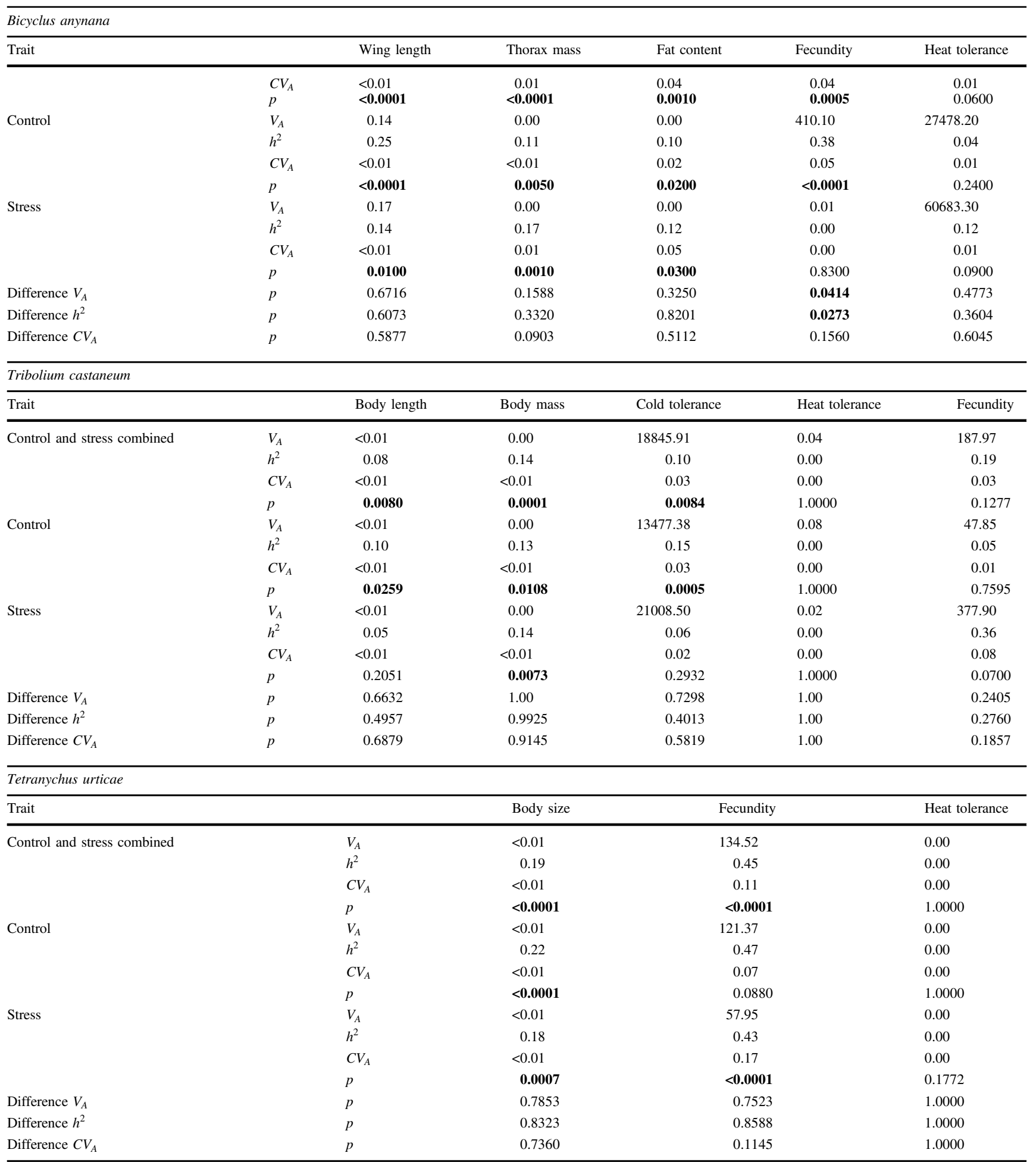

Given are genetic variance $\left(V_{A}\right)$, heritability $\left(h^{2}\right)$ and the coefficient of genetic variation $\left(C V_{A}\right)$, as well as their statistical significance $(p$ value). The combined genetic variation is based on both treatments accounting for the fitted fixed effects. In addition, parameters were estimated separately for the control and stress treatment, respectively. Finally, it was tested whether $V_{A}, h^{2}$ and $C V_{A}$ differ between treatments. Significant $p$ values are given in bold. For full results including fixed effects, residual variance and test statistics see Supplementary Table 2. 


\section{Life history traits $\left(h^{2}\right)$}

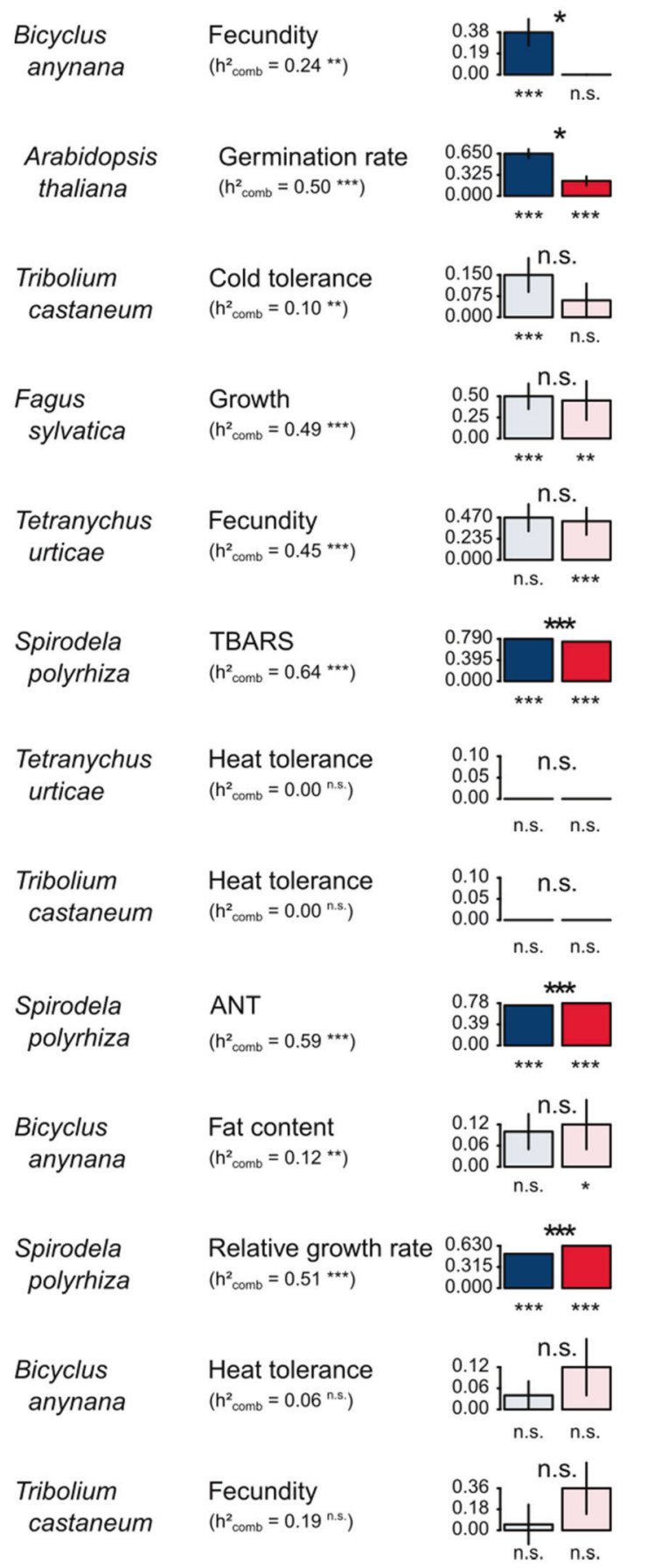

Fig. 1 Estimated heritabilities $\left(h^{2} \pm \mathrm{SE}\right)$ for control (blue) and stress (red) treatment across species and traits. Results are grouped into life-history traits (left panel) and morphological traits (right panel), and are sorted by effect direction and size of $h^{2}$ from control $>$ stress to stress $>$ control. The heritability of both treatments combined, accounting for the fitted fixed effects, is displayed below each trait

significant genetic variation were significantly different among treatments. In addition, there was no pattern with regard to the direction of significant differences among

\section{Morphological traits $\left(h^{2}\right)$}

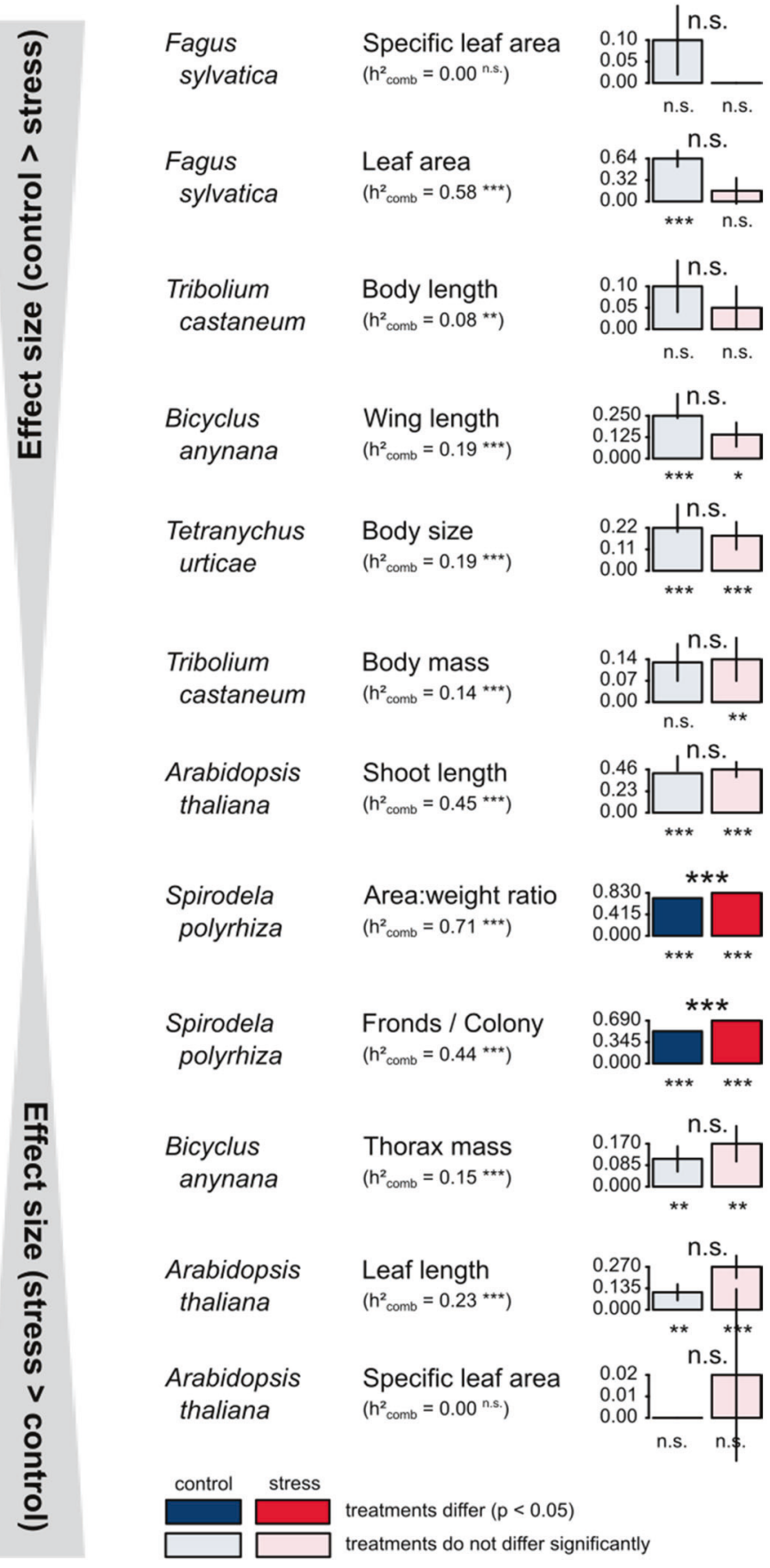

name. Statistical significance for $h^{2}$ within each treatment is indicated below each bar, and the difference in $h^{2}$ between treatments is displayed above bars and is additionally highlighted by the colour intensity of bars. Significance is coded according to $* * * p<0.001 ; * * p$ $<0.01 ; * p<0.05 ; p>0.05$ : n.s. For full results including fixed effects, residual variance and test statistics see Supplementary Table 2.

treatments: under stress, $V_{A}$ increased $4 \times$ and decreased $6 \times$, $h^{2}$ increased $3 \times$ and decreased $4 \times$ and $C V_{A}$ increased $4 \times$ and decreased $4 \times$. Heritability (for cases with significant genetic 
Table 3 Results of metaanalyses for the effects of treatment or trait type on estimated genetic variation in various traits measured in six species.

\begin{tabular}{lllll}
\hline Traits & Effect & $V_{A}$ & $h^{2}$ & $C V_{A}$ \\
\hline All & Treatment & $-0.18(-0.75 / 0.39)$ & $0.10(-0.45 / 0.67)$ & $0.04(-0.53 / 0.61)$ \\
All & Trait type & $-0.40(-0.97 / 0.18)$ & $-0.19(-0.76 / 0.38)$ & $-\mathbf{0 . 6 4}(-\mathbf{1 . 2 2} /-\mathbf{0 . 0 5})$ \\
Morphological & Treatment & $-0.13(-0.98 / 0.72)$ & $0.07(-0.78 / 0.92)$ & $0.16(-0.69 / 1.01)$ \\
Life history & Treatment & $-0.22(-1.03 / 0.59)$ & $0.12(-0.69 / 0.93)$ & $0.05(-0.76 / 0.86)$ \\
\hline
\end{tabular}

Treatment: control vs. stressful conditions; trait type: morphological vs. life history. Given are the traits considered, the tested effect and Hedges $g$ with lower/upper 95\% confidence interval in brackets for additive genetic variance $\left(V_{A}\right)$, narrow-sense heritability $\left(h^{2}\right)$ and the coefficient of genetic variation $\left(C V_{A}\right)$. Significant effects are given in bold. variance) ranged between 0.08 and 0.71 for morphological and between 0.10 and 0.64 for life-history traits (Table 2).

\section{Genetic variation: results of meta-analyses}

In line with the above findings, our meta-analyses showed no significant effects of treatment or trait type on estimates of genetic variation, except for a difference in $C V_{A}$ among morphological and life-history traits (Hedges $g=-0.63$; $95 \%$ confidence interval -1.21 to -0.05 , Table 3 ). Likewise, GLMMs did not reveal significant differences in $V_{A}$ $\left(F_{1,41}=0.39, p=0.538\right), h^{2}\left(F_{1,41}=0.34, p=0.563\right)$ or $C V_{A}\left(F_{1,41}=0.02, p=0.879\right)$ among treatments, and only a significant difference among morphological and life-history traits for $C V_{A}\left(V_{A}: F_{1,41}=1.15, p=0.289 ; h^{2}: F_{1,41}=2.28\right.$, $p=0.139 ; C V_{A}: F_{1,41}=6.34, p=0.016$, Fig. 2). All interactions were non-significant (all $p>0.638$ ).

\section{Discussion}

Investigating the impact of stressful conditions on the expression of genetic variation depends crucially on the following issues: (1) it needs to be shown that the benign control and the stressful conditions have different effects on fitness, i.e., that the stress applied reduced fitness components. (2) There must be significant genetic variation available for the traits in question. We start with addressing both the above issues before proceeding with our main question, namely the effects of thermal stress on the expression of genetic variation.

\section{Effects of treatment on the traits investigated}

Nearly all traits were significantly affected by the stress treatments applied. Regarding morphological traits, higher temperatures increased leaf and shoot length in A. thaliana, likely caused by concomitantly higher metabolic rates (Loveys et al. 2002; Vile et al. 2012). Higher temperature also increased AWR (an analogous value for specific leaf area, SLA) in aquatic $S$. polyrhiza, which might be a compensation for a reduced net-photosynthetic gain under
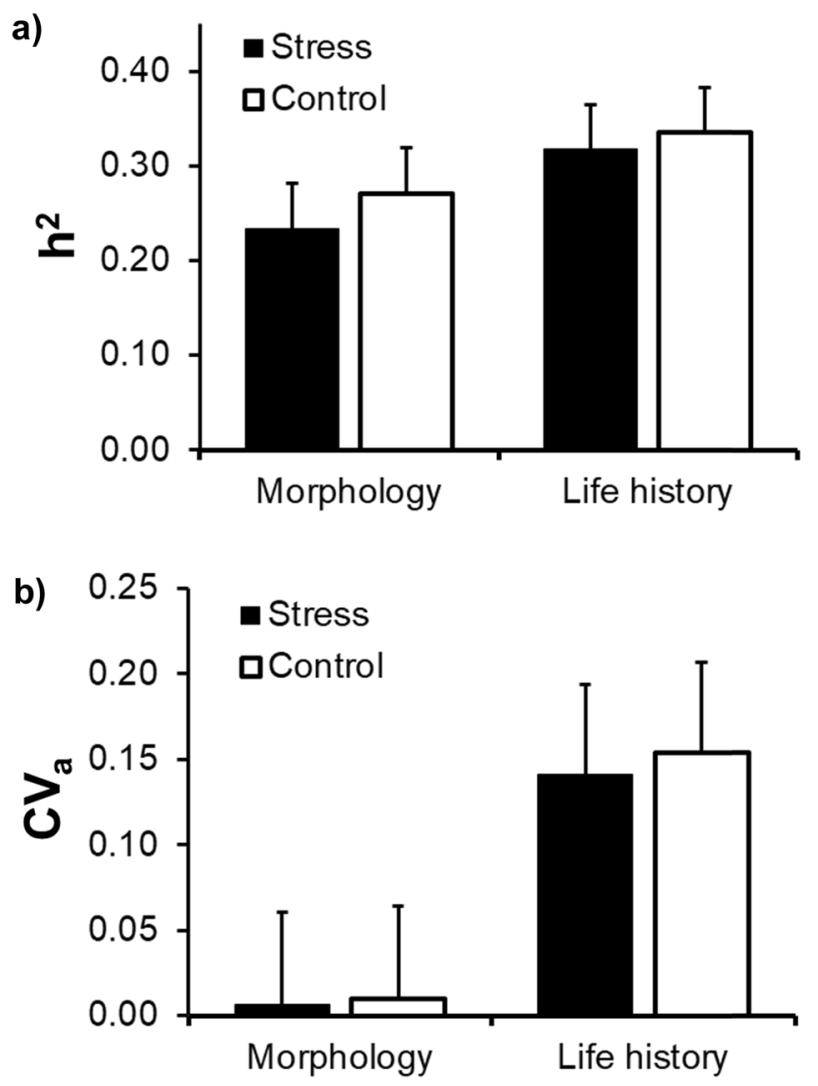

Fig. 2 Effects of stress on heritability and the coefficient of genetic variation. Least-square means $\pm S E$ for a narrow-sense heritability $\left(h^{2}\right)$ and $\mathbf{b}$ the coefficient of genetic variation $\left(C V_{A}\right)$ in relation to treatment and trait type. Data represent six species with 3-5 traits measured per species.

high temperatures (Körner 2006) or a means to increase transpiration cooling (Stewart et al. 2016). In contrast, higher temperatures decreased SLA in terrestrial A. thaliana and $F$. sylvatica and total leaf area in $F$. sylvatica, which may help to reduce water loss (Poorter et al. 2009; Vile et al. 2012). The decreased number of fronds per colony in $S$. polyrhiza may reflect a general stress response (Henke et al. 2011). The mass and size reductions at the higher temperature found in B. anynana and $T$. castaneum reflect a near-universal law in ectotherms, the temperature-size rule (Atkinson 1994; Angilletta et al. 2004). 
Regarding life-history traits, high temperatures increased heat tolerance in $B$. anynana and $T$. castaneum, representing a well-known example of adaptive phenotypic plasticity in arthropods (Fischer et al. 2010, 2011; Santos et al. 2011). Thus, exposure to higher temperatures increases heat and decreases cold tolerance and vice versa, as a short-term response to variable thermal conditions. Such plastic responses may be part of an organism's stress response (Sørensen et al. 2003). However, they are likely to come at energetic costs for the organism (DeWitt et al. 1998; Sgro et al. 2016). Thus, increased heat tolerance is likely not generally beneficial to the organism but only under exposure to heat (Sørensen et al. 2003). The increase in relative fat content at higher temperatures in $B$. anynana was unexpected (cf. Fischer et al. 2014), but may indicate that animals prepared for even worse future conditions by storing more reserves. Importantly, higher temperatures reduced fecundity in all arthropod species, germination rate in A. thaliana, growth rate in S. polyrhiza and $F$. sylvatica and TBARS and ANT in S. polyrhiza. Thus, while morphological traits did not show a clear pattern, life-history traits revealed in all species detrimental effects of the higher temperature on specific fitness components (though not necessarily on all traits considered), and also seemed to induce stress responses. This is despite the fact that for individual traits, it can be difficult to define what is beneficial or detrimental to the organism (Barker and Podger 1970; Niemelä et al. 2012).

\section{Genetic variation in the traits investigated}

Nearly all traits investigated showed significant genetic variation, thus providing variation for natural selection to act upon. The exceptions included fecundity, heat tolerance and specific leaf area, with low levels of genetic variation having been expected at least for both former traits as they are closely related to fitness (Roff 2002). Genetic variation in heat tolerance has been commonly found in ectotherms, though its evolutionary potential is typically low (Hoffmann et al. 2013; Hangartner and Hoffmann 2016; Rolandi et al. 2018). However, the specific trait examined and the experimental protocol used have large impacts on the assessment of genetic variation in heat tolerance (Chown et al. 2009; Hoffmann et al. 2013; Hangartner and Hoffmann 2016). Such issues may cause a failure to detect low levels of genetic variation, which may have contributed to our negative results. Small and non-significant estimates could, of course, also be due to small sample sizes. It should, however, be noted that the samples sizes were large enough to detect even heritabilities as low as 0.10 , and so it seems that the analyses were not generally underpowered (cf. Müller et al. 2003; Fischer et al. 2004; Saastamoinen 2008). Overall, significant genetic variation was thus found for both morphological and life-history traits, with the range of heritabilities matching expected patterns (Falconer and Mackay 1996; Roff 2002). However, we found no support for our second hypothesis, namely that genetic variation is on average higher in morphological than in life-history traits (Roff 2002). In general, levels of genetic variation were very similar across trait types in our study, with the exception of $C V_{A}$ that was, as expected, higher in morphological than life-history traits.

\section{Effects of thermal stress on genetic variation}

Overall, we found no indication that the expression of genetic variation is generally affected by thermal stress (hypothesis 3). The results on the different species and traits revealed that significant differences were found only in a third of all cases (25 of 75 analyses). Moreover, patterns were inconsistent across traits and species, with genetic variation being significantly increased in 11 and decreased in 14 cases under stress. Fifteen out of the 25 significant cases concerned $S$. polyrhiza, in which only clonal repeatability as a proxy of genetic variation could be measured. Note that we included different reproductive modes on purpose in order to cover (at least part of) the wide variety of life histories found in nature. Thus, we have to reject our third hypothesis that thermal stress has predictable effects on genetic variation. Similar results were obtained by Charmantier and Garant (2005), with the majority of 46 traits not showing significant dependence of heritability estimates on the environmental conditions. Nevertheless, there was a trend towards increased heritability under favourable conditions (Charmantier and Garant 2005). In a more recent meta-analysis on animals also, no clear pattern in heritability between stressful and benign conditions was found (Rowinski and Rogell 2017). However, the coefficient of genetic variation was higher under stressful than benign conditions (though only in life-history but not in morphological traits), which contrasts the above opposite finding (Rowinski and Rogell 2017). In our study, finally, we did not find a pattern in either measure of genetic variation, stressing the species- and trait-specific nature of effects.

\section{Conclusions}

Our results show that across three plant and three arthropod taxa (1) the applied stress treatments reduced fitness components, (2) the majority of traits showed significant genetic variation and (3) thermal stress did not affect the expression of genetic variation in a predictable way. This is despite the fact that we used mainly laboratory approaches here, under which heritability is often overestimated due to lower 
environmental but higher additive genetic variance (Geber and Griffen 2003; Charmantier and Garant 2005). Environment-dependent expression of genetic variation has received much attention in recent years, as genetic adaptation may be necessary for successfully dealing with environmental change (Gienapp et al. 2008, 2014), but a covariance between the expression of genetic variation and environmental conditions may lead to different responses to selection, depending on the environment (Hoffmann and Merila 1999; Ghalambor et al. 2007; Rowinski and Rogell 2017; Ramakers et al. 2018). However, in line with other recent studies (Wood and Brodie 2016; Rowinski and Rogell 2017; Ramakers et al. 2018), our data suggest that there is no general impact of thermal stress on the expression of genetic variation under laboratory conditions. Our results are based on six species and 25 morphological and life-history traits, and are not biased by exclusively focussing on trait heritability that is dependent on environmentally sensitive non-genetic sources of variation (Houle 1992; Rowinski and Rogell 2017). We therefore conclude that the potential impact of environmental conditions on the expression of genetic variation may have been overemphasised. The lack of a general pattern in the variation of genetic variation with environmental conditions found here may suggest that the rate of genetic adaptation to environmental change is not generally affected by the environment. Rather, careful case-by-case considerations are needed due to pronounced variation among traits and species.

\section{Data availability}

All data used in our analyses are deposited in the Dryad Digital Repository (https://doi.org/10.5061/dryad. k0p2ngf60).

Funding This research was funded by the DFG research training group RESPONSE (DFG GRK 2010).

\section{Compliance with ethical standards}

Conflict of interest The authors declare that they have no conflict of interest.

Publisher's note Springer Nature remains neutral with regard to jurisdictional claims in published maps and institutional affiliations.

\section{References}

Ågren J, Schemske DW (2012) Reciprocal transplants demonstrate strong adaptive differentiation of the model organism Arabidopsis thaliana in its native range. New Phyt 194:1112-1122

Angilletta MJ, Steury TD, Sears MW (2004) Temperature, growth rate, and body size in ectotherms: fitting pieces of a life-history puzzle. Integr Comp Biol 44:498-509
Appenroth KJ, Teller S, Horn M (1996) Photophysiology of turion formation and germination in Spirodela polyrhiza. Biologia Plantarum 38:95-106.

Atkinson D (1994) Temperature and organism size-a biological law for ectotherms? Adv Ecol Res 25:1-58

Barker JSF, Podger RN (1970) Interspecific competition between Drosophila melanogaster and Drosophila simulans: effects of larval density on viability and adult body size. Ecology 51:170-189

Barnosky A, Matzke N, Tomiya S, Wogan G, Swartz B, Quental T et al. (2011) Has the Earth's sixth mass extinction already arrived? Nature 471:51-57

Bates DM, Sarkar D (2007) lme4: linear mixed-effects models. R package version 0. 9975-13. http://www.R-project.org

Beaulieu M, Geiger RE, Reim E, Zielke L, Fischer K (2015) Reproduction alters oxidative status when it is traded-off against longevity. Evolution 69:1786-1796

Berg MP, Kiers ET, Driessen G, Van der Heijden M, Kooi BW, Kuenen $\mathrm{F}$ et al. (2010) Adapt or disperse: understanding species persistence in a changing world. Glob Change Biol 16:587-598

Borenstein M, Hedges LV, Higgins JPT, Rothstein HR (2009) Introduction to meta-analysis. John Wiley \& Sons, Chichester

Boyd PW, Collins S, Dupont S, Fabricius K, Gattuso JP, Havenhand J et al. (2018) Experimental strategies to assess the biological ramifications of multiple drivers of global ocean change-a review. Glob Change Biol 24:2239-2261

Ceballos G, Ehrlich PR, Barnosky AD, García A, Pringle RM, Palmer TM (2015) Accelerated modern human-induced species losses: entering the sixth mass extinction. Sci Adv 1:e1400253

Ceballos G, Ehrlich PR, Dirzo R (2017) Population losses and the sixth mass extinction. Proc Natl Acad Sci USA 114: E6089-E6096

Charmantier A, Garant D (2005) Environmental quality and evolutionary potential: lessons from wild populations. Proc R Soc B 272:1415-1425

Chevin LM, Lande R, Mace GM (2010) Adaptation, plasticity, and extinction in a changing environment: towards a predictive theory. PLOS Biol 8:e1000357

Chown SL, Jumbam KR, Sørensen JG, Terblanche JS (2009) Phenotypic variance, plasticity and heritability estimates of critical thermal limits depend on methodological context. Funct Ecol 23:133-140

Cvjetko P, Tolić S, Šikić S, Balen B, Tkalec M, Vidaković-Cifrek Ž et al. (2010) Effect of copper on the toxicity and genotoxicity of cadmium in duckweed (Lemna minor L.). Arch Indust Hyg Toxicol 61:287-296

DeWitt TJ, Sih A, Wilson DS (1998) Costs and limits of phenotypic plasticity. Trends Ecol Evol 13:77-81

Falconer DS, Mackay TF (1996) Introduction to quantitative genetics, 4th edn. Benjamin Cummings, Essex

Fischer K, Brakefield PM, Zwaan BJ (2003) Plasticity in butterfly egg size: why larger offspring at lower temperatures? Ecology 84:3138-3147

Fischer K, Bot ANM, Zwaan BJ, Brakefield PM (2004) Genetic and environmental sources of egg size variation in the butterfly Bicyclus anynana. Heredity 92:163-169

Fischer K, Dierks A, Franke K, Geister TL, Liszka M, Winter S et al. (2010) Environmental effects on temperature stress resistance in the tropical butterfly Bicyclus anynana. PLoS One 5:e15284

Fischer K, Klockmann M, Reim E (2014) Strong negative effects of simulated heat waves in a tropical butterfly. J Exp Biol 217:2892-2898

Fischer K, Kölzow N, Höltje H, Karl I (2011) Assay conditions in laboratory experiments: is the use of constant rather than fluctuating temperatures justified when investigating temperatureinduced plasticity? Oecologia 166:23-33 
Geber MA, Griffen LR (2003) Inheritance and natural selection on functional traits. Int J Plant Sci 164:S21-S42.

Ghalambor CK, McKay JK, Carroll SP, Reznick DN (2007) Adaptive versus non-adaptive phenotypic plasticity and the potential for contemporary adaptation in new environments. Funct Ecol 21:394-407

Gienapp P, Reed TE, Visser ME (2014) Why climate change invariably leads to selection on phenology. Proc $R$ Soc $B$ 281:20141611

Gienapp P, Lof M, Reed TE, McNamara J, Verhulst S, Visser ME (2013) Predicting demographically sustainable rates of adaptation: can great tit breeding time keep pace with climate change? Phil Trans R Soc B 368:20120289

Gienapp P, Teplitsky C, Alho JS, Mills JA, Merilä J (2008) Climate change and evolution: disentangling environmental and genetic responses. Mol Ecol 17:167-178

Gurevitch J, Hedges LV (2001) Meta-analysis: combining the results of independent experiments. In: Scheiner SM, Gurevitch J (eds) Design and analysis of ecological experiments. Oxford University Press, New York, p 347-369

Hacket-Pain AJ, Cavin L, Friend AD, Jump AS (2016) Consistent limitation of growth by high temperature and low precipitation from range core to southern edge of European beech indicates widespread vulnerability to changing climate. Eur J Forest Res 135:897-909

Hangartner S, Hoffmann AA (2016) Evolutionary potential of multiple measures of upper thermal tolerance in Drosophila melanogaster. Funct Ecol 30:442-452

Helle W (1967) Fertilization in 2-spotted spider mite (Tetranychus urticae - Acari). Ent Exp Appl 10:103-110

Henke R, Eberius M, Appenroth KJ (2011) Induction of frond abscission by metals and other toxic compounds in Lemna minor. Aquatic Toxicol 101:261-265

Hoffmann AA, Chown SL, Clusella-Trullas S (2013) Upper thermal limits in terrestrial ectotherms: how constrained are they? Funct Ecol 27:934-949

Hoffmann AA, Merila J (1999) Heritable variation and evolution under favourable and unfavourable conditions. Trends Ecol Evol 14:96-101

Hoffmann AA, Parsons PA (1991) Evolutionary genetics and environmental stress. University Press, Oxford

Hoffmann AA, Sgro CM (2011) Climate change and evolutionary adaptation. Nature 470:479-485

Hoffmann AA, Sgrò CM, Kristensen TN (2017) Revisiting adaptive potential, population size, and conservation. Trends Ecol Evol 32:505-517.

Houle D (1992) Comparing evolvability and variability of quantitative traits. Genetics 130:195-204

Janero DR (1990) Malondialdehyde and thiobarbituric acid-reactivity as diagnostic indices of lipid peroxidation and peroxidative tissue injury. Free Radical Biol Med 9:515-540

Jump AS, Hunt JM, Penuelas J (2006) Rapid climate change-related growth decline at the southern range edge of Fagus sylvatica. Glob Change Biol 12:2163-2174

Kellermann V, van Heerwaarden B, Sgrò CM, Hoffmann AA (2009) Fundamental evolutionary limits in ecological traits drive Drosophila species distributions. Science 325:1244-1246

Klockmann K, Günter F, Fischer K (2016) Heat resistance throughout ontogeny: body size constrains thermal tolerance. Glob Change Biol 23:686-696

Körner C (2006) Significance of temperature in plant life. In: Morison JIL, Morecroft MD (eds) Plant growth and climate change. Blackwell Publishing, Oxford, p 48-69

Kruuk LEB (2004) Estimating genetic parameters in natural populations using the 'animal model'. Phil Trans R Soc B 359:873-890
Landolt E (1986) The family of Lemnaceae—a monographic study. Stiftung Ruebel, Zürich

Larsen TB (1991) The butterflies of Kenya and their natural history. University Press, Oxford

Lenoir J, Svenning J-C (2014) Climate-related range shifts-a global multidimensional synthesis and new research directions. Ecography $38: 15-28$

Leuschner C, Meier IC, Hertel D (2006) On the niche breadth of Fagus sylvatica: soil nutrient status in 50 Central European beech stands on a broad range of bedrock types. Ann For Sci 63:355-368

Loveys BR, Scheurwater I, Pons TL, Fitter AH, Atkin OK (2002) Growth temperature influences the underlying components of relative growth rate: an investigation using inherently fast- and slow-growing plant species. Plant Cell Environ 25:975-988

Magri D, Vendramin GG, Comps B, Dupanloup I, Geburek T, Gomory D et al. (2006) A new scenario for the quaternary history of European beech populations: palaeobotanical evidence and genetic consequences. New Phytol 171:199-221

Mahroof R, Subramanyam B, Eustace D (2003) Temperature and relative humidity profiles during heat treatment of mills and its efficacy against Tribolium castaneum (Herbst) life stages. J Stored Prod Res 39:555-569

Merilä J, Kruuk LEB, Sheldon BC (2001) Cryptic evolution in a wild bird population. Nature 412:76-79

Mitchell-Olds T, Schmitt J (2006) Genetic mechanisms and evolutionary significance of natural variation in Arabidopsis. Nature 441:947-952

Moritz C, Agudo R (2013) The future of species under climate change: resilience or decline? Science 341:504-508

Müller C, Zwaan BJ, de Vos H, Brakefield PM (2003) Chemical defence in a sawfly: genetic components of variation in relevant life-history traits. Heredity 90:468-475

Naumann B, Eberius M, Appenroth KJ (2007) Growth rate based dose-response relationships and EC-values of ten heavy metals using the duckweed growth inhibition test (ISO 20079) with Lemna minor L. clone St. J Plant Physiol 164:1656-1664

Niemelä PT, Vainikka A, Hedrick AV, Kortet R (2012) Integrating behaviour with life history: boldness of the field cricket, Gryllus integer, during ontogeny. Funct Ecol 26:450-456

Ørsted M, Hoffmann AA, Sverrisdóttir E, Lehmann Nielsen K, Kristensen TN (2019) Genomic variation predicts adaptive evolutionary responses better than population bottleneck history. PLoS Genetics 15:e1008205

Poorter H, Niinemets U, Poorter L, Wright IJ, Villar R (2009) Causes and consequences of variation in leaf mass per area (LMA): a meta-analysis. New Phytol 182:565-588

Ramakers JJC, Culina A, Visser ME, Gienapp P (2018) Environmental coupling of heritability and selection is rare and of minor evolutionary significance in wild populations. Nature Ecol Evol 2:1093-1103

Roff DA (2002) Life history evolution. Sinauer Associates, Oxford

Rolandi C, Lighton JRB, de la Vega GJ, Schilman PE, Mensch J (2018) Genetic variation for tolerance to high temperatures in a population of Drosophila melanogaster. Ecol Evol 8:10374-10383

Rowinski PK, Rogell B (2017) Environmental stress correlates with increases in both genetic and residual variances: a meta-analysis of animal studies. Evolution 71:1339-1351

Saastamoinen M (2008) Heritability of dispersal rate and other life history traits in the Glanville fritillary butterfly. Heredity 100:39-46

Sala OE, Chapin FS, Armesto JJ, Berlow E, Bloomfield J, Dirzo R et al. (2000) Biodiversity - global biodiversity scenarios for the year 2100. Science 287:1770-1774

Santos M, Castañeda LE, Rezende EL (2011) Making sense of heat tolerance estimates in ectotherms: lessons from Drosophila. Funct Ecol 25:1169-1180 
Sgro CM, Terblanche JS, Hoffmann AA (2016) What can plasticity contribute to insect responses to climate change? Annu Rev Entomol 61:433-451

Sims DA, Gamon JA (2002) Relationships between leaf pigment content and spectral reflectance across a wide range of species, leaf structures and developmental stages. Remote Sensing Environ 81:337-354

Sørensen JG, Kristensen TN, Loeschcke V (2003) The evolutionary and ecological role of heat shock proteins. Ecol Lett 6:1025-1037

Stewart JJ, Demmig-Adams B, Cohu CM, Wenzl CA, Muller O, Adams WW (2016) Growth temperature impact on leaf form and function in Arabidopsis thaliana ecotypes from northern and southern Europe. Plant Cell Environ 39:1549-1558

Thomas CD, Cameron A, Green RE, Bakkenes M, Beaumont LJ, Collingham YC et al. (2004) Extinction risk from climate change. Nature 427:145-148

Torchiano M (2017) effsize: efficient effect size computation, R package version 0.7.1. https://CRAN.R-project.org/package=effsize

Tsuda T, Shiga K, Ohshima K, Kawakishi S, Osawa T (1996) Inhibition of lipid peroxidation and the active oxygen radical scavenging effect of anthocyanin pigments isolated from Phaseolus vulgaris L. Bioch Pharm 52:1033-1039
Van Leeuwen T, Vanholme B, Van Pottelberge S, Van Nieuwenhuyse P, Nauen R, Tirry L et al. (2008) Mitochondrial heteroplasmy and the evolution of insecticide resistance: non-Mendelian inheritance in action. Proc Natl Acad Sci USA 105:5980-5985

Vile D, Pervent M, Belluau M, Vasseur F, Bresson J, Muller B et al. (2012) Arabidopsis growth under prolonged high temperature and water deficit: independent or interactive effects? Plant Cell Environ 35:702-718

Wilson AJ, Réale D, Clements MN, Morrissey MM, Postma E, Walling CA et al. (2010) An ecologist's guide to the animal model. J Anim Ecol 79:13-26

Wood CW, Brodie ED (2016) Evolutionary response when selection and genetic variation covary across environments. Ecol Lett 19:1189-1200

Wood JL, Yates MC, Fraser DJ (2016) Are heritability and selection related to population size in nature? Meta-analysis and conservation implications. Evol Appl 9:640-657

Ziegler P, Adelmann K, Zimmer S, Schmidt C, Appenroth KJ (2015) Relative in vitro growth rates of duckweeds (Lemnaceae) - the most rapidly growing higher plants. Plant Biol 17:33-41 